\title{
Digital Radiography: Comparison of Different Methods for Imaging of the Thorax and the Gastrointestinal Tracts
}

\author{
H.P. Busch
}

In evaluating the image quality of the chest, four different analog and digital methods were compared. For peripheral lung field, the advanced multiple beam equalization radiography (AMBER) system was given the best score, followed in order by the storagephosphor, conventional, and asymmetric film/screen systems. For the mediastinal field, the highest image quality was given to the AMBER system, followed by storage phosphor and asymmetric film/screen system. The best overall image quality, especially with regard to demonstration of pathologic alteration, was given to the AMBER system, followed by the storagephosphor, conventional, and asymmetric film/screen radiography systems. In conclusion, AMBER demonstrated the highest image quality. The storage-phosphor system provided better results in the peripheral and mediastinal fields in comparison with conven. tional film/screen systems. Other digital systems including selenium chest radiography system and image intensifier digital radiography were also discussed. Copyright $\odot 1995$ by W.B. Saunders Company

KEY WORDS: AMBER system, storage phosphor system, conventional film/screen system, asymmetric film/screen system, image intensifier digital radiography.

I RECENT years, new digital and analog techniques have been used to improve the quality of chest films. In a clinical study and in routine use, five different analog and digital methods were compared by phantoms and patient examinations ${ }^{1}$ (Table 1 ).

\section{MATERIALS AND METHODS}

Conventional film/screen radiographs were obtained on a bucky stand. The operating parameters were $117 \mathrm{kVp}$; film/focus distance, $2 \mathrm{~m}$; grid $12 / 40$, film/screen and speed, 200 frames per second (fps).

For an asymmetric film/screen system, we used the same imaging parameters, and nearly the same dose. The combination of InSight film/screen (Eastman Kodak, Rochester, NY) uses dual-reception sensitometry by front and back screens with different sensitivities. This dual-receptor approach gives an anatomic-specific contrast dependency and improves sensitivity especially in the areas with low transmission (eg, the retrocardial space).

Address reprint requests to H.P. Busch, MD, Krankenhaus der Barmherzigen Brüder, Nordallee 1, D-54292 Trier, Ger many.

Copyright $(1995$ by W.B. Saunders Company

0897-1889/95/0801-1003\$3.00/0
Conventional film/screen exposures are limited by the small exposure range. For chest radiograph imaging, large transmission differences between the various parts of the lung are necessary. Large absorption differences can be equalized with the new equalization technique (AMBER) using local exposure control. The AMBER system is a variation of slit technique. The narrowly collimated beam is divided into 21-beam segments. The multielement $x$-ray modulator controls the intensity profile along a scanning fan-shaped beam in response to measurements from a linear detector array in front of the film cassettes. This results in chest radiographs that are well exposed in the lung parenchyma and the mediastinum. ${ }^{2}$

Storage-phosphor radiography systems (Philips PCR, Philips Medical Systems; Fuji AC1+, Fuji Medical Systems, Tokyo, Japan) are mainly used for emergency imaging, but additionally for imaging of the chest and skeleton. For this study, exposure of the thorax was performed at a wall stand with the same exposure parameters used in conventional film/screen images.

As a second digital imaging technique, image intensifier radiography was used for chest radiographs. A Polytron system (Siemens Medical Systems, Inc, Iselin, NJ) was connected to a large image intensifier. The diameter of the entrance field was $157 \mathrm{~cm}$, the matrix size, $1,024 \times 1,024$. For digital image intensifier radiography, the spatial resolution was measured at 0.9 line pairs (lp) $/ \mathrm{mm}$. Of course, this resolution is too low for chest imaging. Therefore, digital image intensifier radiography was a subject of a previous study, but was excluded from this comparison of image quality in studies of patients.

An important part of our study was the comparison of image quality in patient examinations. Forty-three patients were examined simultaneously by conventional film/screen, InSight, AMBER, and storage-phosphor systems. Images were evaluated by seven experienced radiologists from four different radiology departments. Radiologists graded the image quality obtained by these different methods using the following criteria for the mediastinal and peripheral lung fields. Mediastinal field: retrocardiac lung structures, vertebral column, tracheal bifurcation, right paratracheal stripe, and aorta descendens; peripheral field: peripheral lung structures (right upper field), peripheral lung structures (right lower field), hilus structures, and lateral pleural line.

The observers simultaneously evaluated all four images of the patient at a light box. Observers were advised to rank the best imaging method as number 1 and then classify the other methods with numbers 2 through 4. Equal image quality had to be given the same rank.

\section{RESULTS}

The results are shown in Table 2. On summary of the total points for peripheral field, the AMBER system was given the best score, ie, the lowest rank sum, followed in order by the 
Table 1. Analog and Digital Techniques for Imaging of the Thorax

\begin{tabular}{ll}
\hline \multicolumn{1}{c}{ Analog Techniques } & \multicolumn{1}{c}{ Digital Techniques } \\
\hline Conventional film/screen & Image Intensifier radiography \\
Asymmetric film/screen & Storage phosphor radiography \\
Equilization technique & \\
\hline
\end{tabular}

storage-phosphor, conventional, and asymmetric film/screen systems. For the mediastinal field, the highest image quality was given to the AMBER system, followed by storage-phosphor and asymmetric film/screen systems. The best overall image quality, especially with regard to demonstration of pathologic alteration, was given to the AMBER system, followed by the storage-phosphor, conventional, and asymmetric film/screen radiography systems.

In conclusion, AMBER demonstrated the highest image quality. The storage phosphor system provided better results in the peripheral and mediastinal fields in comparison with conventional film/screen systems.

\section{COMMENTS}

At the German Roentgen Congress 1994, initial experiences and applications of selenium as a new image detector for chest radiography were discussed. Selenium seems to be a promising new technology for digital chest radiography. The detector itself is a layer of amorph selenium. Selenium, as a photoconductor, stores the image information as an electric-charge image. Scanning takes place capacitively. The image information is then stored in digital form. The main advantages in comparison with con-

Table 2. Comparison of Image Quality

\begin{tabular}{lc}
\hline \multicolumn{1}{c}{ System } & Rank Sum \\
\hline Peripheral field & 56 \\
1. Amber & 66 \\
2. Storage phosphor & 72 \\
3. Conventional film/screen & 81 \\
4. Asymmetric film/screen & \\
Mediastinal field & 46 \\
1. Amber & 76 \\
2. Storage phosphor & 76 \\
3. Asymmetric film/screen & 102 \\
4. Conventional film/screen & \\
Classification of the total quality & 60 \\
1. Amber & 73 \\
2. Storage phosphor & 94 \\
3. Conventional film/screen & 97 \\
4. Asymmetric film/screen &
\end{tabular}

ventional storage-phosphor systems are lower scattering within the detector and significantly lower noise. ${ }^{3}$ This results in a high-quality image.

Digital image intensifier radiography has been a well-known technique since the first clinical application of digital subtraction angiography (DSA). For fluoroscopic examination units, conventional film/screen radiography has been increasingly replaced by digital image intensifier radiography in recent years. Some units can be used for DSA as well as for projection radiography. In Mannheim, a Polytron system (Siemens) has been used for DSA and digital projection radiography since $1987 .^{4-7}$ The unit works in a two-room installation and is connected to a remote-control system (Siregraph D, Siemens) and a large intensifier with a diameter of $57 \mathrm{~cm}$ (Optilux 57, Siemens).

Indications for digital I.I. radiography are examinations of the gastrointestinal tract, phlebography, intravenous pyelography, arthrography, hysterosalpingography, control of catheters and tubes, interactive measurements, and functional studies (eg, esophagus).

For digital radiography, dose can be selected in a broad range. This means that the radiation dose for the patient can be adapted to the diagnostic problem and to the necessary image quality. By automatic control, the image brightness is nearly independent of the dose. This is in contrast with film/screen radiography, but because of physical laws, a lower dose is connected to a lower signal/noise ratio.

Therefore, it is necessary to answer a question: What is the lowest dose necessary for special diagnostic problems?

For double-contrast examination of the stomach, the small bowel, and the colon with the highest image quality, the selected dose was about $40 \%$ of a film/screen combination (speed, $200 \mathrm{fps}$ ). For functional gastrointestinal examination in pediatrics, the selected dose was about $3 \%$ of a conventional film/screen system (speed 200 ). In general, the dose for digital I.I. radiography is significantly lower than for conventional film/screen radiography, especially for large entrance fields.

Advantages of digital image intensifier radiography in comparison with film/screen radiography are a decrease in dose, immediate image 
demonstration on monitors, and economical documentation by lowering the number of films and the possibilities for post processing, storage, and transfer of digital information. Disadvantages involve the low spatial resolution for large image intensifier diameters and the additional equipment (Table 3). Compared with film/screen radiography, digital image intensifier radiography is a further step to reduce patient discomfort by shorter examination time

Table 3. Advantages and Disadvantages of Digital Image Intensifier Radiography

Advantages
Direct image demonstration
Dose reduction
Possibilities of postprocessing
Economical advantages for documentation
Storage and transfer of digital images
Disadvantages
Lower spatial resolution for large image intensifier diam-
eters
Additional equipment

and lower dose, to reduce costs and last, but not least, to improve the quality of the examination.

For optimal results in digital radiography, high-performance systems with continuous quality control are necessary. Quality assurance requires reproducible performance measurements that are not time consuming, with limited additional equipment. For high image quality, it is important that the whole imaging chain has a high performance level including documentation and film processing. Digital radiography provides new possibilities to determine image quality on a numerical base (eg, signal/noise ratio).

In many of the examination methods used in radiology, image information is already recorded, processed, and stored in digital form by computers. Further developments aim to integrate various equipment into an entire digital concept such as the picture archiving and communication system (PACS). Digital image intensifier radiography and storage phosphor radiography will have an increasing impact on clinical radiography in the future.

\section{REFERENCES}

1. Busch HP, Lehmann KJ, Drescher P, et al: New chest imaging techniques: A comparison of five analogue and digital methods. Eur Radiol 2:342-345, 1992

2. Schulze-Kool LJ, Busscher DL, Vlasbloem $\mathrm{H}$, et al: Advanced multiple beam equalization radiography in chest radiology; simulated nodule detection study. Radiology 169:35-39, 1988

3. Neitzel U: Selenium-A new imaging detector for digital chest radiography. MedicaMundi 38:89-93, 1993

4. Busch HP, Georgi M (eds): Digital RadiographyClinical Experiences with Digital Image Intensifier and
Storage Phosphor Radiography. New York, NY, Blackwell, 1992

5. Busch HP, Georgi M: Digitale Radiographie-Illusion oder Zukunftsperspektive?, in Günther RW, Gockel HP (eds): Jahrbuch der Radiologie. Zülpich, Germany, Biermann Verlag, 1991, pp 47-66

6. Busch HP, Georgi M: Digital Radiography. Quality assurance and radiation protection. Radiol Diagn 33:321324,1992

7. Lehmann KJ, Busch HP, Georgi M: Digital fluoroscopic radiology: Evaluation of the clinical impact. Eur $J$ Radiol 17:3-7, 1993 